\title{
HOW TO DESIGN A WEB SURVEY USING SPRING BOOT WITH MYSQL: A ROMANIAN NETWORK CASE STUDY
}

\author{
Rocsana BUCEA-MANEA-ȚONIȘ ${ }^{1}$, Radu BUCEA-MANEA-ȚONIȘ ${ }^{2}$ \\ I"Spiru Haret" University, Faculty of Economic Sciences, Fabricii Street, no. \\ 46G, Bucharest, 030045, Romania, Tel.: +40213169793, Fax: +40213169793, \\ Email:mk.rocsana.bucea@spiruharet.ro \\ ${ }^{2}$ Hyperion University, Călăraşilor Road, no. 169, Sector 3, Bucharest, \\ 030615,Romania, Tel.: +4021.327.44.64, Fax: +4021.321.62.96, \\ Email: rocsense44@yahoo.com
}

\begin{abstract}
The article presents a survey applied on a representative sample of Romanian SMEs. The article represents a case study and focus on technical elements that allow collecting data from Romanian SMEs managers and save it in a MySql database. The Back-End component is developed with the newest Spring Boot MVC.
\end{abstract}

Keywords: survey, MVC, Spring Boot, MySql database, Romanian SMEs. JEL Classification: $\mathrm{M}_{15}$

\section{Introduction}

The article presents the technical implementation on collecting data during a survey for Romanian SMEs. The scope of the survey is to find out the level of awareness and the knowledge of SMEs on ICT facilities. The survey analysis and interpretations will be published publicly and send to each SME, in order to help surpass the current technological challenges. Another scope is to help SMEs to be more adapted to market requirements.

\section{Research methodology}

During the survey the Romanian SMEs are interviewed regarding:

A: General information: company name, headquarters of the institution, phone, e-mail, geographic area, activity area, name of person who completed the questionnaire-mail the person who completed the questionnaire 

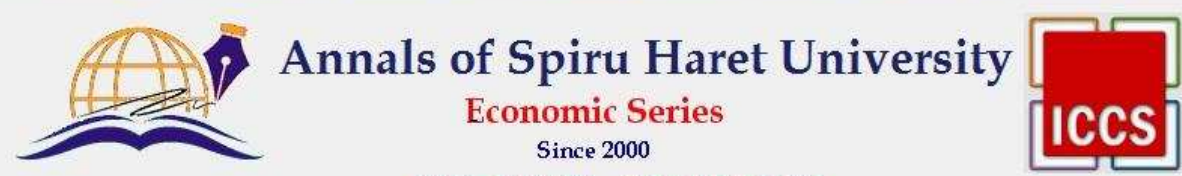

Issue 2/2017

\section{B: IT \& $C$ data}

- What management system the company chosen and paying ratings on a scale from 1 (very poor) to 5 (best) for the following attributes related to the management information system: functionality (ability to respond specifically to program a task), reliability (the program's ability to maintain performance levels respecting given conditions), ergonomics (ease of use and learning using the program), effective management of time and space required memory execution, Maintainability (stability execution after making changes), portability (the extent to which the application can run on systems other than the one it was originally made).

- What business intelligence solution and accounting program (licensed or open source) the company chose.

- If the management information system is designed by IT specialists within the company what tools used for building them? Does the company indent to add more functional modules or to change the application?

\section{C: Data regarding the On Line presence of the company}

- What is the role of the internet in defining managerial objectives of the company? Which are the sites that the company often visits? Is the company a member of a forum/blog or other portal discussion on topics of business? Does the company maintain correspondence internet business? How does the company identify the investment opportunities, etc.

\section{D: Economic data}

There were gathered data regarding the number of enterprise employees, turnover in 2007, the share in turnover of institution, annual budget that was allocated to software solutions or hardware, the value of company's export and imports.

The companies were asked if the financial indicators have improved once deployed application and which are the items to base on the development of the company. They also were pleased to indicate what types of European funds had accessed and to mention three main positive and negative events that the company recorded in the past years.

\section{E: Data on IT\&C awareness}

The companies were investigated regarding the awareness of free open source licensed software, such as: Open Office package, Linux-Apache-PHP Mysq, Saga, SpagoBI, etc. 
Issue $2 / 2017$

\section{Front end component}

The client side contains a HTML form, named chestionar that sends users answers by fill in the form through GET http method:

The form elements are:

1. Textboxes, such as:

Denumirea, sediul institutiei, telefon, adresa de e-mail: $\langle$ br $\rangle<$ input name="T1" type="text" id="T1" size="60" $>\langle$ br $>$

2. Drop down lists, such as:

1. Ce sistem informatic pentru management ati ales pentru companie (sistem informatic de asistarea deciziei)?<br $>$

$<$ select id="siad" name="siad" >

$<$ option>Alegeti

$<$ option value $=1>1$. Dicodess - orientare pe modele;

$<$ option value $=2>2$. NetMeeting - orientare pe comunicare;

$<$ option value $=3>3$. Groove - orientare pe comunicare;

$<$ option value $=4>4$. Sphinx- orientare pe anliza datelor;

$<$ option value $=5>5$. Altele - specificati numele

$<$ option value $=6>6$. Nicu unul (nu utilizam )

$</$ select $\rangle\langle$ br $>$

Specificati in aceasta casuta care este raspunsul pentru altele $<$ br $><$ input name="T4" type="text" id="T4" size="30" $>\langle$ br $>\langle$ br $>$

3. Lists, such as:

2. Acordati calificative pe o scala de la 1 (foarte slab) la 5 (foarte bun) pentru urmatoarele atribute referitoare la sistemul informatic de management:

$<\mathrm{ul}>$

$<$ li $>$ functionalitate (capacitatea programului de a raspunde precis la o sarcina) <select id="f1" name="f1">

$</$ select $>\langle$ br $>$

$<$ li $>$ fiabilitate (capacitatea programului de a-si mentine nivelul de performanta respectand conditiile date)

<select id="f2" name="f2"> 
Issue 2/2017

\section{$</$ select $\rangle\langle$ br $>$}

4. Textarea, that allows a longer open answer for user, such as:

12. Care sunt facilitatile software pe care NU vi le ofera solutiile software utilizate de companie si care considerati ca ar influenta benefic activitatea companiei?<br $>$

$<$ textarea name="facil" id="facil" rows="4" cols="60" $\rangle\langle/$ textarea $\rangle\langle$ br $\rangle$

Ce site-uri vizitati? $<$ br $><$ textarea name $="$ sites" id="sites" rows="4" cols $=" 60 "></$ textarea $>$

\section{Check boxes, for choosing yes/no answers}

$\langle\mathrm{li}\rangle\langle\mathrm{b}\rangle$ Bifati casuta alaturata daca doriti sa publicam pe acest site numele si scurta descriere a companiei dvs \&nbsp;

<input type="checkbox" id="bifa" name="bifa" value="bifat" $\rangle\langle$ br $/\rangle\langle$ br $/\rangle$

\section{Submission button}

Va rugam, apasati acest buton pentru a salva raspunsurile dvs.<input type="button" onclick="valid_sondaj()" name="raspunsuri" value="Trimite" $1>\langle$ br $>\langle$ br $></$ form $>$

The result of the previous code is the questionnaire form presented in the picture below (fig.1.): 


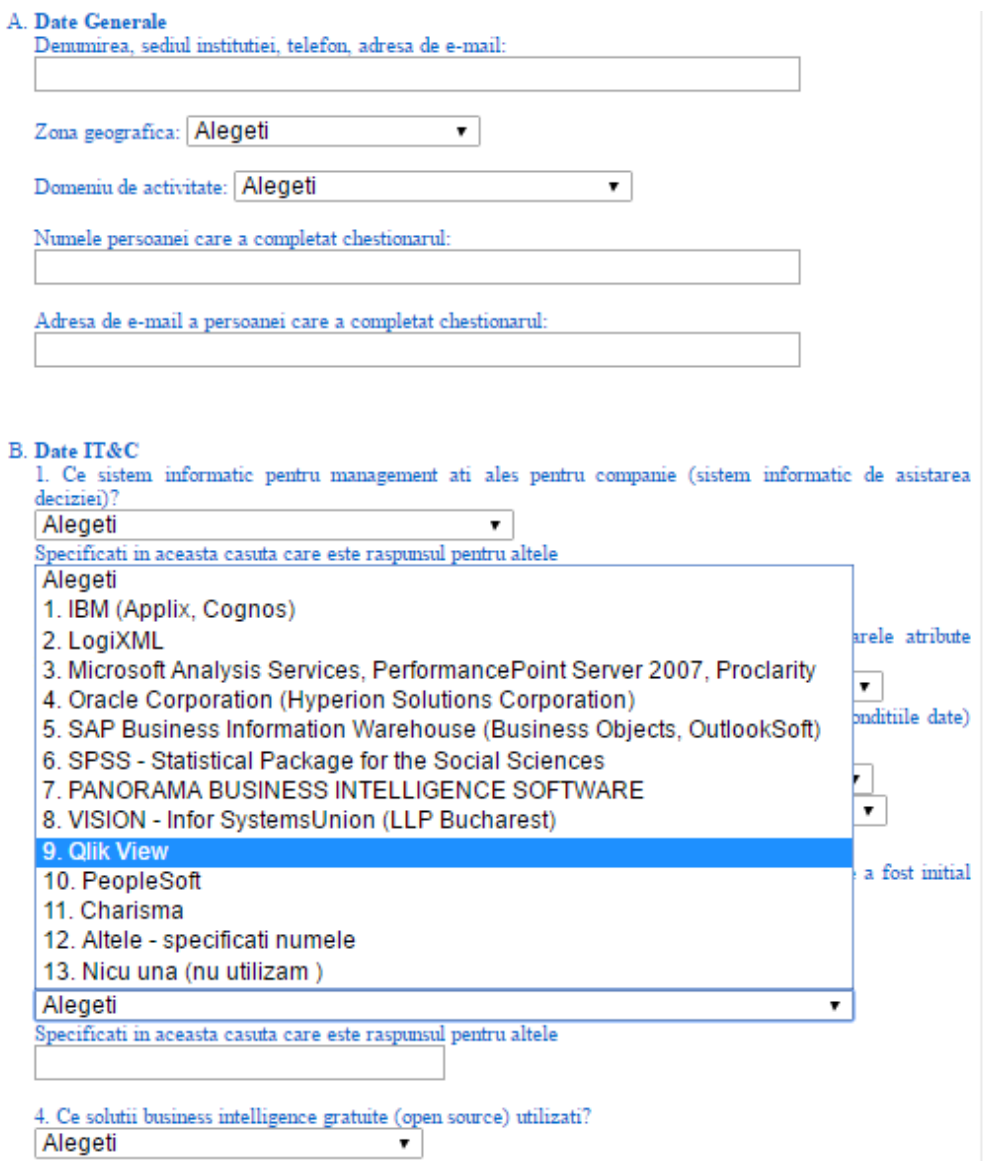

Figure no. 1. Form presented to Romanian SMEs manager to fill in

\section{Back end component}

MySQL create table directive is shown below:

create table chestionar ( id MEDIUMINT PRIMARY KEY AUTO_INCREM ENT, T1 varchar(60) NOT NULL, zona varchar(20) NOTNULL, dom varchar(20)

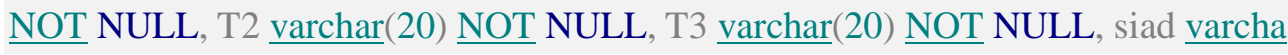


Issue 2/2017

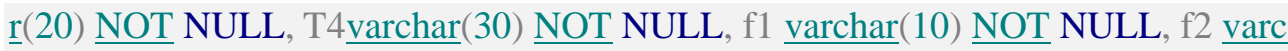
har(10) NOT NULL, f3 varchar(10) NOT NULL, f4 $\operatorname{varchar}(10)$ NOT NULL, f5 va rchar(10) NOT NULL, f6 varchar(10) NOT NULL, facil varchar(250) NOT NULL , bifa bit NOT NULL, tsTIMESTAMP DEFAULT CURRENT_TIMESTAMP)

The result can be seen in the next image:

\begin{tabular}{|c|c|c|c|c|}
\hline & $\#$ & Name & Type & Collat| \\
\hline 氤 & & $\underline{\text { Id }}$ & mediumint(9) & \\
\hline Q & & $\mathrm{T} 1$ & $\operatorname{varchar}(60)$ & latin1 \\
\hline ( & & zona & varchar(20) & latin1 \\
\hline$\square$ & & dom & varchar(20) & latin1 \\
\hline$\square$ & & T2 & varchar(20) & latin1 \\
\hline$\square$ & 6 & $\mathrm{~T} 3$ & varchar(20) & latin1 \\
\hline 0 & & slad & varchar(20) & latin1_ \\
\hline G & & $\mathrm{T} 4$ & varchar $(30)$ & latin1 \\
\hline 回 & & f1 & varchar(10) & latin1 \\
\hline$\square$ & 10 & $\mathrm{f} 2$ & varchar(10) & latin1 \\
\hline 미 & 11 & & varchar(10) & latin1 \\
\hline D & 12 & $f 4$ & $\operatorname{varchar}(10)$ & latin1 \\
\hline & & & & Int: \\
\hline
\end{tabular}

Figure no. 2. Chestionar MySQL table

We are using Spring Boot MVC for deploying the web application. The Model component is detailed below.

This annotation tells Hibernate to make a table out of this class:

@Entity

public class chest \{ 

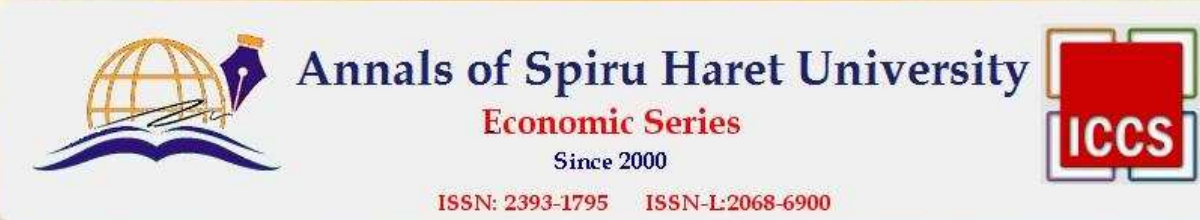

ISSN: 2393-1795 ISSN-L:2068-6900

Issue 2/2017

The following annotation helps identify id field as a unique identifier or primary key:

\section{@Id}

The next annotation is for automated increment of the id field:

@ GeneratedValue(strategy=GenerationType.AUTO)

This following block of code contains the fields that map the table in the database:

$$
\begin{aligned}
& \text { private Integer id; } \\
& \text { private String T1; } \\
& \text { private String zona; } \\
& \text { private String dom; } \\
& \text {... } \\
& \text { private java.util.Date ts; }
\end{aligned}
$$

The getters and setters employed for the CRUD methods implementation are shown below:

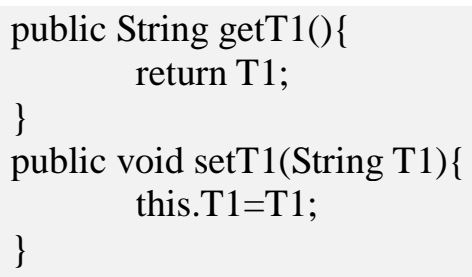

The Controller implements two methods: one for adding one questionnaire at a time (addNewChest), and one to show all the questionnaires (getAllChest).

package hello;

$\cdots$

import hello.chest;

import hello.UserRepository;

@ Controller // This means that this class is a Controller

@ RequestMapping(path="/demo") // This means URL's start with /demo (after Application path) 
Issue $2 / 2017$

public class MainController \{

@ Autowired // This means to get the bean called userRepository

// Which is auto-generated by Spring, we will use it to handle the

data

private UserRepository userRepository;

@ GetMapping(path="/add") // Map ONLY GET Requests

public@ResponseBody String addNewChest (@RequestParam String

T1,@RequestParam String zona,...,@RequestParam String bifa) \{

//@ ResponseBody means the returned String is the response, not a view name

//@RequestParam means it is a parameter from the GET or POST

request

chest $\mathrm{n}=$ new $\operatorname{chest}()$;

n.setDom(dom);

...

n.setZona(zona);

userRepository.save(n);

return "Saved";

\}

@ GetMapping(path="/all")

public@ @esponseBody Iterable<chest> getAllChest() \{

// This returns a JSON or XML with the users

\}

return userRepository.findAll();

\}

When the application starts, it recreates the table in MySQL (thus erasing all the previously recorded data!) and the Tomcat web server waits for clients to connect:

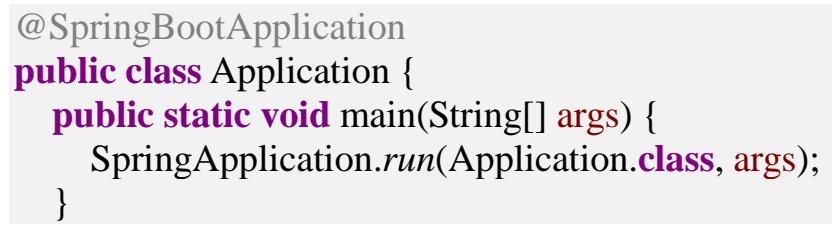



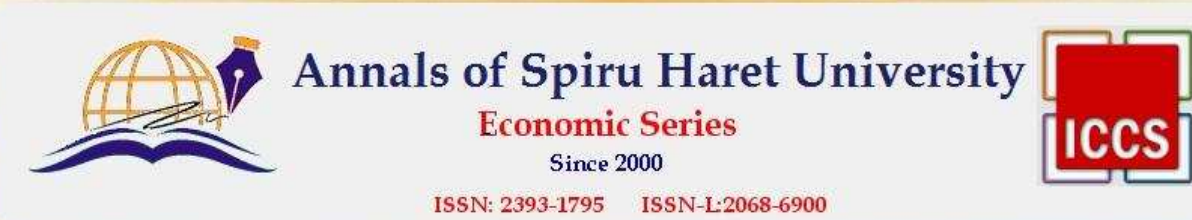

ISSN: 2393-1795 ISSN-L:2068-6900

Issue $2 / 2017$

\}

The configuration file used for this application contains the following information:

spring.jpa.hibernate.ddl-auto=create

spring.datasource.url=jdbc:mysql://localhost:3306/Chestionare

spring.datasource. username $=$ root

spring.datasource.password=

All the elements in the HTML page are associated with fields in Java. For example, the String T1 field that requests the content from the T1 text box $(<$ input name $=$ "T1" type = "text" id = "T1" size = "60">) using GET http method, like in the form below:

$<$ form name="chestionar" id="sondajfrm" method="get" action="demo/add" $>\langle$ font color=\#0066CC $>\quad<$ ol type="A" $>\langle\mathrm{li}\rangle\langle\mathrm{b}>$ Date Generale $</ \mathrm{b}><\mathrm{br}>\ldots . .</$ font $>$

To ensure that all fields are filled in, survey validations are implemented on each field, as presented in the code below:

<script type="text/javascript">

function valid_sondaj( $)\{$

if (document.getElementById('sondajfrm').T1.value==") alert('Va rugam sa completati datele referitoare la companie!');

else if (document.getElementById('sondajfrm').dom.value=='Alegeti') alert('Va rugam sa completati domeniul de activitate!');

else if (document.getElementById('sondajfrm').T2.value==") alert('Va rugam sa completati numele dvs!');

else if (document.getElementById('sondajfrm').oportun.value=='Alegeti') alert ('Va rugam sa completati cum descoperiti oportunitatile de investitii!'); 
Issue $2 / 2017$

else if (document.getElementById('sondajfrm').outsourcing.value=='Alegeti') alert ('Va rugam sa completati ce forma de outsourcing a ales compania!');

else if (document.getElementById('sondajfrm').ind.value=='Alegeti') alert('Va rugam sa completati ce indicatori s-au imbunatatit!');

else document.getElementById('sondajfrm').submit();

\}

$</$ script $>$

\section{Further research}

In a future paper, it will be presented the survey interpretation and conclusions in order to offer support and consultancy on ICT facilities for SMEs.

\section{Conclusions}

The article is an original research representing a case study of technical solutions to implement an html form that sends collected data from end-users in a MySql database through GET HTTP method. Thus any SMEs can follow the steps above and use the code presented for collecting different type of data on internet and send it into their own database. There are free web forms on the market, but they set a limit in the number of collected questionnaires. 